\section{Economía Social y Solidaria. Una mirada desde las políticas públicas locales}

Mariano Cuvertino

Guillermo Cherner

Dirección de Economía Social,

Municipalidad de Santa Fe, Argentina
Economía Social y Solidaria /

Desafíos de gestión

RECEPCIÓN: 26/06/15

ACEPTACIÓN FINAL: 03/09/15

\section{Resumen}

El trabajo es una descripción de las políticas públicas llevadas adelante por la Municipalidad de Santa Fe con relación al crecimiento y la consolidación del trabajo autogestivo, vinculado con los conceptos y las nociones de la Economía Social y Solidaria (ESS). En el artículo se detallan las estrategias elaboradas en conjunto con distintos actores del Estado, como es el caso del gobierno de la provincia de Santa Fe y de la Universidad Nacional del Litoral (UNL), con la creación del Centro de Emprendedores de la Economía Social en la ciudad de Santa Fe. Se detallan también las intervenciones realizadas en la búsqueda de herramientas que posibiliten la inclusión socioproductiva como política de Estado y los desafíos que deberá afrontar el gobierno local en la consolidación de esas políticas.
Palabras clave

- Economía Social y Solidaria

- políticas públicas

- comercialización

- producción

- gobierno local

\section{Resumo}

O trabalho é uma descrição das políticas públicas realizadas pelo governo da cidade de Santa Fe em relação ao crescimento e à consolidação do trabalho de autogestão, ligado com os conceitos e as noções da Economia Social e Solidária. No artigo detalham-se as estratégias preparadas em conjunto com diferentes atores do Estado, como é o caso do Governo Provincial e da Universidade Nacional do Litoral (UNL), com a criação do Centro de Empresários da Economia Social na cidade de Santa Fe. Detalham-se também as intervenções realizadas na procura de ferramentas que possam permitir a inclusão socioprodutiva como política do Estado e os desafios que devem ser enfrentados pelo governo local na consolidação dessas políticas.

\section{Palavras-chave}

- Economia Social e Solidária

- políticas públicas

- comercialização

- produção

- governo local
Para citación de este artículo

Cuvertino, M. y Cherner, G. (2015). Economía Social y Solidaria. Una mirada desde las políticas públicas locales. En Revista +E versión digital, (5), pp. 150-156. Santa Fe, Argentina: Ediciones UNL. 


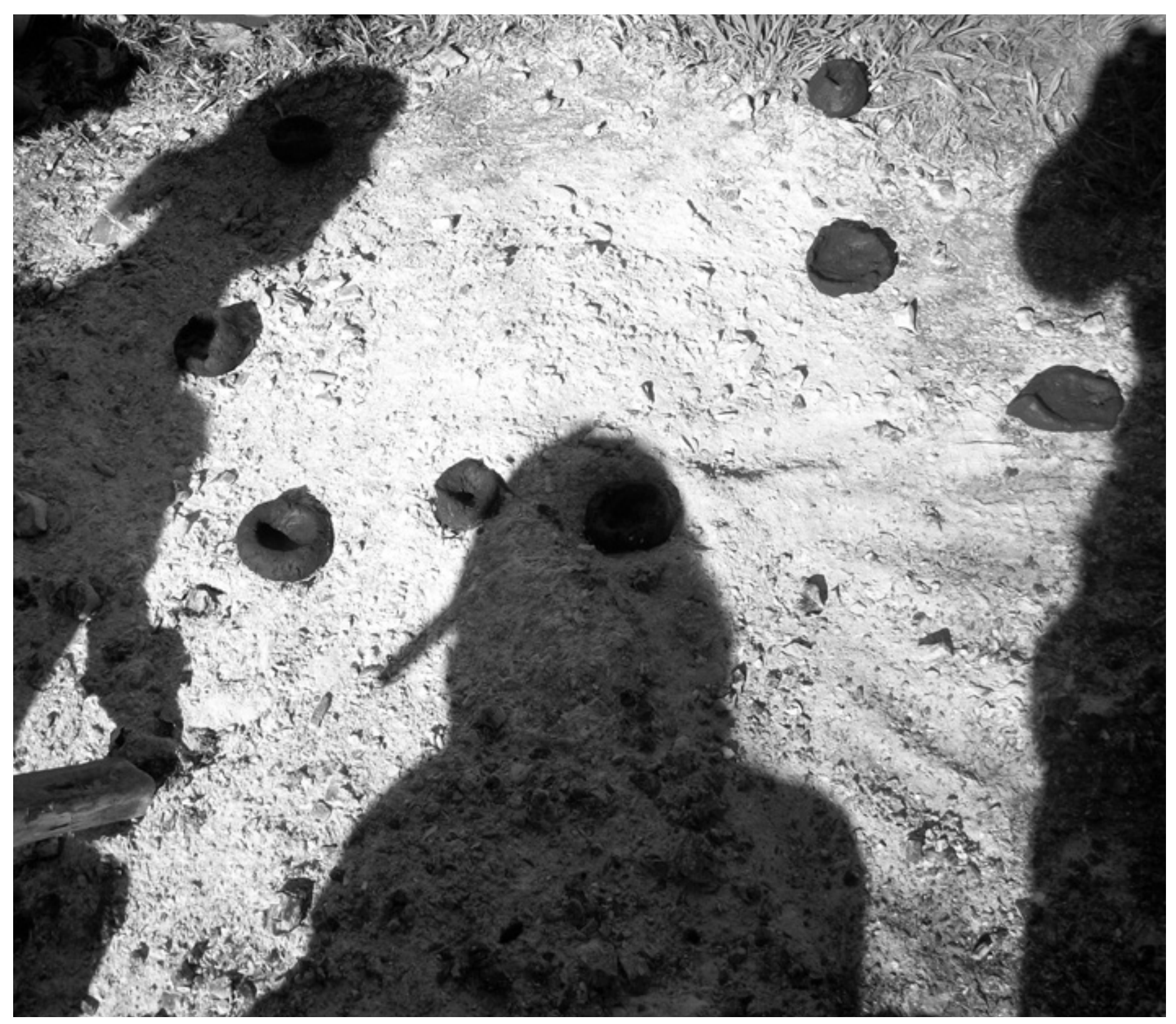




\section{Algunas ideas sobre Economía Social y Solidaria}

La Economía Social y Solidaria (ESS) es un concepto que ha ido cobrando fuerza en los últimos tiempos. El auge de la ESS estuvo signado mayoritariamente por el fracaso de las políticas públicas orientadas hacia los sectores populares y ante la necesidad de reconstruir socialmente los lazos y valores con los que desarrollamos nuestra producción y nos organizamos para satisfacer las necesidades humanas.

José Luis Coraggio afirma que es en la ESS donde

"el desarrollo de la vida de las personas y comunidades es favorecido por la acción colectiva en ámbitos locales, donde los conflictos de intereses y la competencia pueden ser regulados de manera más transparente en el seno de la sociedad, donde las relaciones interpersonales fraternales puedan afianzarse sobre vínculos productivos y reproductivos de cooperación, generando asociaciones libres de trabajadores antes que empresas en las que el trabajo es subordinado al capital autoritario por la necesidad de obtener un salario para sobrevivir" (2011:43).

El autor presenta una mirada social de la economía, que produce sociedad y no exclusivamente utilidades económicas.

De allí que entendamos a la ESS como un conjunto de agentes que se organizan de diferentes formas asociativas, en las que prima el interés general por sobre el individual, donde prevalece el trabajo por sobre el capital y se generan lazos solidarios de diferentes tipos que permiten la democratización de las prácticas económicas. En Argentina, los orígenes de la ESS se remontan a las ideas traídas desde Europa por las oleadas de inmigrantes a finales del siglo XIX, que desarrollaron marcos cooperativos y de asociativismo como método organizativo para sus desarrollos económicos regionales. Dichos procesos conformaron los inicios del movimiento cooperativo en Argentina, que actualmente compone un segmento destacado de la economía nacional. ${ }^{1}$

Sin embargo, fue a fines de los años 90 y durante los años que siguieron a la crisis del año 2001 cuando se generaron profundos desarrollos de nuevos emprendimientos productivos organizados por desocupados, trabajadores precarizados, excluidos sociales y asociaciones civiles dentro del marco de la ESS. Estos nuevos emprendimientos de la ESS no encontraron un Estado preparado para dar respuestas y/o herramientas a sus necesidades. Se tornó imperante, entonces, el desarrollo de nuevas estrategias de políticas públicas y una necesaria revisión por parte del Estado de la forma de abordar la temática.

\section{La ESS como política local}

En el caso de la Municipalidad de Santa Fe, es en las últimas dos gestiones ${ }^{2}$ y al calor de los avances tanto en la esfera nacional como provincial, donde se tomaron las decisiones políticas necesarias para comenzar con el desarrollo y aplicación de políticas públicas de ESS.

En una primera etapa se dio inicio al diseño y aplicación de políticas, a partir de la creación del Programa Puente en el año 2009, como una política de promoción del empleo y trabajo autogestivo. ${ }^{3}$ A fines del 2013, la voluntad política del gobierno local de seguir jerarquizando y fortaleciendo el desarrollo de políticas públicas en ESS se manifiesta en la creación de la Dirección de Economía Social de la Municipalidad de Santa Fe.

Desde esta Dirección, se trabaja en el desarrollo y fortalecimiento de pequeñas unidades productivas dirigidas a satisfacer las necesidades de los diferentes grupos sociales. El propósito es desarrollar capacidades de inserción productiva y comercial, propiciando el encadenamiento productivo solidario y fortaleciendo el capital social. Estas condiciones generan entramados socioproductivos con valores y prácticas características de la ESS. La identificación, promoción, financiamiento y acompañamiento de experiencias en territorios priorizados, permiten a los ciudadanos adquirir competencias de trabajo autogestivo y llevar adelante emprendimientos sustentables en el tiempo. Esta tarea se lleva adelante en conjunto con vecinales, cooperativas, empresas sociales y otras instituciones de la sociedad civil para incentivar y fortalecer a los emprendedores en cada uno de los barrios

\section{El Centro de Emprendedores de la Economía Social: una experiencia novedosa y exitosa}

A mediados del 2013 se crea el Centro de Emprendedores de la Economía Social (CEES) cogestionado entre el gobierno de la provincia de Santa Fe, la Municipalidad de la ciudad y la UNL. El Centro es un ámbito de referencia que promueve la cooperación
1) Según el Instituto Nacional de Asociativismo y Economía Social (INAES), las cooperativas registradas en el país son 14760 en total, con cerca de 9 millones de asociados a las mismas. De acuerdo con estimaciones del organismo, las empresas y entidades de la economía social (mutuales y coo- perativas) generan 500000 puestos de trabajo y aportan cerca del $10 \%$ del $\mathrm{PBI}$ de la Argentina.

2) Primer período de gobierno diciembre $2007 /$ diciembre de 2011 y segundo período de gobierno diciembre 2011/diciembre 2015.

3) El Programa Puente surgió a fines del año 2009 en el marco de las políticas de promoción del empleo y el autoempleo que llevo adelante la Dirección de Trabajo y Empleo de la Municipalidad de Santa Fe. La experiencia tenía por objeto generar dispositivos para la promoción de emprendimientos productivos sociales, abarcando diversas modalidades de organización económica e integrando a sujetos que comparten el hecho de que su actividad productiva destinada al mercado surge como proyecto para mejorar sus condiciones de vida. 


\author{
C \\ la identificación, promoción, \\ financiamiento y acompañamiento de \\ experiencias en territorios priorizados, \\ permiten a los ciudadanos adquirir \\ competencias de trabajo autogestivo \\ y llevar adelante emprendimientos \\ sustentables en el tiempo
}

entre agentes, instituciones y organismos públicos y privados para el diseño y ejecución de emprendimientos de la ESS en la ciudad. Desde el CEES se trabaja en la identificación de las unidades productivas y se las incorpora en el Registro de Emprendedores Productores Locales de la ciudad de Santa Fe (REPLO). ${ }^{4}$ En este Registro pueden inscribirse los titulares de emprendimientos, individuales o asociativos, de carácter productivo. A partir de allí, comienza un proceso en el que se brindan a los registrados distintos tipos de servicios con el fin de fortalecer a la ESS en general y a cada uno de sus actores en particular.

\subsection{Espacios de comercialización}

Desde el CEES se promueven ferias, eventos y espacios para la exposición y comercialización de productos y servicios, que se convierten a su vez, en ámbitos de encuentro e intercambio entre los distintos actores de la ESS de la región.

A su vez, se gestionan espacios específicos de promoción propia, como es la Feria de la Ciclovía, que funciona los domingos de 15:00 a 19:00 hs. en el Parque Federal de la ciudad. En la Feria participan aproximadamente 50 emprendedores que comercializan sus productos y comparten el espacio con actividades culturales y recreativas que fortalecen el ámbito común de encuentro. El Mercado Norte de la ciudad constituye otro espacio de comercialización de 15 emprendedores vinculados al CEES. Este espacio fue reinaugurado el año pasado, convirtiéndose en una experiencia única y de importante promoción para algunos productores de la Feria de la Ciclovía.
Actualmente se está trabajando en el desarrollo de una plataforma virtual de comercialización desarrollada por un grupo de investigadores de la cátedra de ESS de la Facultad de Ciencias Económicas de la UNL en conjunto con la Cooperativa de Trabajo Colectivo Libre Ltda. basada en los valores de consumo responsable, comercio solidario y precio justo. ${ }^{5}$

\subsection{Capacitación y asistencia técnica}

Se trata de instancias pensadas para otorgar a los emprendedores las herramientas básicas de gestión para el desarrollo de las iniciativas productivas. Estas instancias se realizan de manera semestral o en jornadas específicas con temáticas concretas. Así se los capacita y asiste técnicamente tanto en aspectos generales como específicos, en forma de talleres:

- Formación inicial: son espacios introductorios para emprendedores que están iniciando su emprendimiento productivo. - Formación integral: se trabaja en torno a diversas herramientas de gestión y organización del emprendimiento.
4) Ordenanza Municipal $N^{\circ} 11641$. 5) Proyecto de Desarrollo Tecnológico y Social CIN-CONICET No 086. 
- Formación específica: se trabaja en torno a temáticas específicas de interés para los emprendedores, (fotografía, serigrafía, recursos creativos, identidad audiovisual, redes sociales y comercio digital, embalaje sustentable, armado de puestos, etcétera).

\subsection{Banco Solidario}

Mediante esta política se permite a las pequeñas unidades productivas acceder a microcréditos bajo la metodología de garantía solidaria, previa conformación de grupos de trabajo de entre tres a cinco miembros. Su objetivo es de facilitar el acceso al crédito a quienes estén imposibilitados de hacerlo en el sistema financiero tradicional y además, fortalecer el capital social y propiciar los valores y prácticas de la ESS (solidaridad, la cooperación, el asociativismo y el trabajo autogestivo).

Para acceder a esta herramienta se toma como requisito haber completado el Taller de Formación Integral.

El microcrédito se utiliza para la compra de materias primas y maquinaria para el fortalecimiento del emprendimiento socioproductivo.

\subsection{La Bitácora ${ }^{6}$}

Se trata de una acción pensada para fortalecer aquellos emprendimientos que ya han transitado un recorrido y se han vinculado al CEES desde las restantes herramientas propuestas. Apunta a trabajar la sostenibilidad de las prácticas productivas, priorizando el intercambio entre emprendedores y equipos técnicos desde una perspectiva participativa, de comprensión mutua y resolución conjunta. Opera en torno de tres momentos de encuentro e intercambio: el primero es el de «Mapeo colectivo», cuyo fin es el de reconocer a los emprendedores y el rubro al que se dedican. El segundo son los «Radares de seguimiento», espacio grupal proyectado al análisis del funcionamiento del emprendimiento y la identificación de problemáticas generales, en busca de soluciones integrales. Finalmente, el tercer espacio denominado «La brújula» es un espacio de acompañamiento personal, donde el equipo técnico organizado en áreas nodales (producción y costos; comercialización; comunicación; marcos regulatorios; acción colectiva) indaga en conjunto con el emprendedor en la búsqueda de encontrar respuestas a las problemáticas del emprendimiento.

\section{La inclusión socioproductiva como política de Estado. Programa Ideas en Marcha}

Las políticas públicas de inclusión frecuentemente se topan con diversos obstáculos tanto en su conceptualización como en su desarrollo. Pocas veces se prioriza en la formulación de las mismas la promoción de proyectos de trabajo autogestivo así como la innovación en las estrategias de acompañamiento que permitan dar un salto de la simple capacitación en oficios o en la intermediación laboral.

No es una cuestión menor que muchos de los destinatarios de estas propuestas han sido excluidos del sistema formal por diversas razones: por la escasa o nula calificación en términos de saberes actuales con incidencia en el mercado; por razones familiares, personales, de salud, por edad o género o de otra índole. El denominador común es la dificultad de insertarse en el medio privado con los requisitos que esto implica.

Para abordar este segmento de la población y en el marco de la decisión política de afrontar esta nueva realidad social es que se definieron las distintas estrategias de trabajo. La mayor parte de ellas se incluyó dentro del Programa Ideas en Marcha, que forma parte de la aplicación del Plan Abre, ${ }^{7}$ y cuyo fin es el de la promoción de emprendimientos socioproductivos en barrios priorizados de la ciudad, brindando la formación, capacitación, acompañamiento y financiamiento a mayores de 16 años. El Plan se enmarca dentro del eje "Convivencia y participación", cuyo objetivo es el de promover la convivencia, fortalecer las instituciones y acompañar las trayectorias de vida de los ciudadanos de los conglomerados urbanos priorizados.
6) Surge del Proyecto de Extensión de Interés Social (UNL) «De la Autogestión al Asociativismo: elaboración de un sistema de apoyo para el acompañamiento a pequeñas unidades productivas en el marco de la ESyS» (Res № 394/14). 7) Plan ABRE: es el Programa de Intervención Integral en Barrios que el Gobierno de la Provincia de Santa Fe implementa a partir del año 2014, en coordinación con las municipalidades de Santa Fe, Rosario, Villa Gobernador Gálvez, Santo Tomé y Pérez. Esta iniciativa tiene como objetivo profundizar un conjunto de acciones tendientes a mejorar la calidad de vida, la convivencia y la seguridad de todos los ciudadanos, a través de dos ejes de trabajo: «Infraestructura y hábitat» y «Convivencia y participación». 
El Programa Ideas en Marcha se inició en el año 2014, con más de 150 personas de diferentes barrios de la ciudad (San Lorenzo, Centenario, San Jerónimo, Varadero Sarsotti, Arenales, Chalet y Santa Rita) y cuya metodología de trabajo fue la siguiente:

1) Talleres de orientación ocupacional, que ayudan a la persona alcanzar su meta laboral, trabajando en la elaboración de su perfil y permitiendo una mejor inserción en el mundo del trabajo;

2) Capacitaciones en oficios, donde se brindan las herramientas y habilidades que posibilitan el inicio del emprendimiento. Se desarrollaron formaciones en: herrería, carpintería, diseño textil, gastronomía, cerámica y marroquinería;

3) Espacios de producción colectiva, donde luego de concluido el proceso de capacitación se disponen los talleres para el uso de los participantes de manera gratuita, con el fin de que estos comiencen a elaborar sus producciones primigenias con financiamiento de los insumos por parte del Estado.

En el año 2015 se decidió de manera conjunta con el gobierno provincial dar un salto de escala al Programa y abordar la totalidad de los barrios incluidos en el Plan Abre de la ciudad: Centenario, San Lorenzo, Santa Rosa de Lima, Barranquitas, Villa Hipódromo, Las Flores, Yapeyú, Acería, Coronel Dorrego, Alto Verde y El Pozo. Se incorporaron 250 participantes a la versión 2015 del Programa, a razón de 25 por barrio. La convocatoria se efectuó a aquellas personas que alguna vez iniciaron el trámite en el REPLO, pero que no habían continuado con su emprendimiento, al menos en los últimos dos años, sumado a la interacción con las distintas instituciones propias del lugar (vecinales, centros comunitarios, de jubilados, etc.) y del Estado (Centros de Atención Familiar, Centros de Salud, dependencias del Ministerio de Desarrollo Social, etc.), que fueron acercando personas con interés por este tipo de labores y que no se encontraba en vínculo con el CEES.

Recientemente, se incorporó la figura del "Promotor barrial" de la ESS, que opera territorialmente en conjunto con los participantes y las instituciones en el propio barrio, facilitando la organización en el lugar de las actividades brindadas y acompañando el proceso del desarrollo del emprendimiento productivo en permanente articulación con el CEES y la búsqueda del fortalecimiento y expansión de las prácticas de la ESS. En el período de inscripciones al Programa, y como característica distintiva de la propuesta, cada Promotor visitó previamente a cada uno de los interesados de manera personal, a diferencia de lo que ocurre frecuentemente donde el interesado debe ir hasta la dependencia oficial.

El Programa incluyó instancias de formación y capacitación para el desarrollo de emprendimientos, compuesta por cinco encuentros en cada uno de los barrios, donde se trabajaron las siguientes temáticas:

1) Proyecto de vida y proyecto laboral. La planificación: objetivos, metas, recursos y actividades.

2) Análisis de costos. Estrategias de eficiencia y reducción de costos. Costos de amortización.

3) Planificar la producción: El proceso productivo. Comercialización. 4) Marcos regulatorios. Adecuación a normas.

5) Economía Social y Emprendedurismo. Tipo de actividad. Bienes y servicios.

Las mismas fueron dictadas por docentes de la UNL que trabajan en vinculación con el CEES.

Las capacitaciones incorporan el acompañamiento para la planificación del desarrollo del emprendimiento productivo de cada participante, con el fin de poder visualizar la mejor manera de fortalecerlo, para luego sí, poder recibir financiamiento por parte del Estado para la compra de maquinarias y materias primas.

En la siguiente etapa se prevé la conformación de grupos de emprendedores barriales en donde se trabajará el concepto de asociativismo, para lograr una mejor integración de los actores en el propio territorio. A su vez, se propone la concreción y realización de ferias de emprendedores locales, en las que se apuesta a la consolidación de un mercado cercano, el propio barrio. Durante todo el proceso, habrá un asesoramiento constante ante las necesidades surgidas en vinculación e integración con las herramientas que brinda el CEES. 


\section{Conclusiones y desafíos: animándose a crecer}

El final de una gestión, renovada por la voluntad popular, es siempre una buena excusa para convertirla en una etapa de balances, análisis y reflexiones de lo que ocurrió, pero particularmente para trazar nuevos objetivos y desafíos a afrontar en el futuro.

La primera y gran conclusión de estos casi ocho años de desarrollo de políticas públicas desde el gobierno local es el haber contribuido a la visibilización de una importante cantidad de personas y familias que encuentran en la ESS no sólo un sustento de vida sino, y fundamentalmente, la forma de materializar saberes, ideas, técnicas y valores que contribuyen al acervo cultural de una sociedad y a la autorrealización de miles de personas. Las casi 1000 unidades productivas que fueron registradas y atravesaron diferentes instancias de trabajo y participación son una muestra contundente del potencial que la ESS tiene en nuestra ciudad.

De esta manera se han identificado las necesidades de ordenar y coordinar el establecimiento de líneas de acción para fortalecer la gestión de aquellas unidades productivas ya en funcionamiento, -adonde apuntan fundamentalmente las políticas desarrolladas en el CEES-. Además, se ha logrado establecer también programas -como Ideas en marcha - que apuntan a identificar, acompañar y consolidar la voluntad y deseo de muchas personas que, encontrándose fuera del mercado laboral, encuentran en la ESS la manera de expresar sus saberes a la vez que encontrar la forma de garantizar la reproducción de sus condiciones materiales de vida. Una necesidad concreta que deberá necesariamente generar un interés en el futuro, es la implementación de acciones dirigidas a fortalecer y mejorar los procesos productivos, así como su producto final. La ESS está en condiciones de exhibir y comercializar productos de excelencia que se equiparen a los que surgen de cualquiera de los otros sectores económicos existentes. La Bitácora, entre otros, se inició con ese claro objetivo. Son importantes los cimientos ya construidos por cada una de las acciones que se fueron desarrollando en pos de fortalecer experiencias de este tipo. La dinámica del trabajo en grupo para contar con el microcrédito del Banco Solidario y la experiencia de promoción de productos en el Espacio de comercialización del Mercado Norte, son experiencias novedosas que contribuyen a poder fomentar, acompañar y financiar en el futuro procesos autogestivos de mayor escala y magnitud como la conformación de Bancos de insumos para la adquisición de los mismos en grandes escalas o poder desarrollar verdaderos consorcios de comercialización, por sólo mencionar alguno de los grandes desafíos a futuro.

Por último, con Ideas en marcha no sólo se logró la identificación, acompañamiento, formación y financiamiento de incipientes unidades productivas sino que, fundamentalmente, permitió dotar a las políticas en ESS de una mayor escala social e inserción territorial de las mismas. Evidentemente es en este sentido donde deberán ser puestos los mayores esfuerzos en un futuro para poder lograr la consolidación de las políticas públicas locales en ESS, y su coordinación con otros niveles del estado, dotando a las mismas de la necesaria fortaleza y potencia para la etapa de desarrollo de la ESS en la ciudad de Santa Fe y su área metropolitana. La referencia alcanzada por el CEES, es un excelente punto de partida.

\section{Referencia bibliográfica}

Coraggio, J.L. (2011). Economía social y solidaria. El trabajo antes que el capital. Quito: Abya-Yala. 